\title{
Women in Hotel Management and Leadership: Diamond or Glass?
}

\author{
Evangelia Marinakou \\ Royal University for Women, Riffa, Kingdom of Bahrain
}

\begin{abstract}
Although the hospitality industry shows growth, only few women are found in high managerial positions. The hotel sector is dominated by women with an average $55.5 \%$ of the workforce, but is managed by men, as women are mainly found in positions that are stereotypically ascribed to their gender, such as directors of sales, housekeeping, and marketing. Fifteen male and 15 female managers in 5-star hotels in Greece were interviewed to explore their management and leadership styles, as well as any challenges they face in the career ladder in hotel management. The findings of this study suggest that women are equally capable to their male counterparts and they acquire skills that are considered to be more effective in the context of the hospitality industry. They are nurturing, better at communicating with people, they are caring, and they adopt supporting behaviors. This paper proposes that hotels that have women in managerial positions are more successful in facing the increasing competitiveness and adapt to changes more efficiently.
\end{abstract}

Keywords: women in management, leadership, hospitality, glass ceiling

\section{Introduction}

Tourism has been considered to be a major contributor to the Greek economy (Papalexandris, 2008) and is considered as a major employer with 659,000 jobs in 2004 , representing $16.5 \%$ of the total employment in the country (International Labor Office [ILO], 2009). Nevertheless, women have the lowest female participation rate in employment in tourism in the country (Eurostat, 2009). Although research has been conducted in hotel management, very little research has been conducted to explore the position of women in hotel management and its effectiveness (Baum, 2013). In addition, Mihail (2006) suggested that there is a lack of updated empirical research on the position of women in corporate Greece. This paper aims at presenting the position of women in hotel management and leadership in the hotel sector in Greece. The main purpose is to present how hotels in Greece may benefit from the way women manage and use their talents and leadership skills in facing the challenges of today's competitive environment which, as Erkutlu (2008) recommended, constantly changes and is characterized by uncertainty and unpredictability.

\section{Women in Hotel Management and Leadership}

Within this changing and challenging environment, changes in the workforce and employability are evident and required. Amongst other factors such as geographical and cultural distances (Nickson \& Warhurst,

Evangelia Marinakou, head of Business, Faculty of Business and Financial Sciences, Royal University for Women. Email: emarinakou@ruw.edu.bh. 
2001), the increasing numbers of women in employment have changed the face of hospitality organizations. According to the ILO (2009), over 200 million people are employed in the hospitality and tourism industry, and women represent 55.5\% (Baum, 2013). Women employed in the hotel sector in Greece are found to represent 45.3\% of the total employment, confirming that the sector employs mainly women (Eurostat, 2009). Nevertheless, there are few women found in high managerial positions (Li \& Leung, 2001) and only in the last decade, women were allowed to climb the managerial ladder in Greek management (Mavridis, 2002).

Women in Greece have lower earnings than their male colleagues, and it ranges from $65 \%$ to $80 \%$ of the men's salary (Pettraki-Kottis \& Ventoura-Neokosmidi, 2004). In addition, others claim that gender stereotypes persist in Greece and prevent women from attaining managerial positions (Vakola \& Apospori, 2007; Pettraki-Kottis \& Ventoura-Neokosmidi, 2004; Ntermanakis, 2003). The region may play a role in the gender attitudes, and perhaps the race and the ethnicity as well (Scott, 1995), as Mihail (2006, p. 688), for example, claimed that the gender stereotypes in Greece stem from the "patriarchal society of modern Greece". He also claimed that "women who aspire to managerial careers in corporate Greece are likely to face intense attitudinal barriers" (Mihail, 2006, p. 690). Organizations in a patriarchal society show "hegemonic masculinity" that refers to practices that legitimate the power of men over women (Thomas, 2005). Under these conditions, women are always in the position of being outsiders, of being "travelers in a male world" (Marshall, 1984, p. 25).

Additionally, it has been argued that women in certain situations adopt appropriate behaviors and roles adapted to the context in which they operate (Biswas \& Cassell, 1996). In other situations, women have the opportunity to express themselves and operate according to their traditional roles (Brownell, 1994a; 1994b). Hence, as Kinnaird and Hall (1994) and Jordan (1997) suggested, the hospitality and tourism industry is influenced by gender stereotyping and therefore, there are certain types of work that women can do. They continued that women are mainly found in part-time or seasonal jobs in tourism. There are certain positions that are dominated by women and others by men. Still, women in this case hold positions that would not allow them to progress in the hierarchy and become hotel general managers (Woods \& Viehland, 2000; Biswas \& Cassell, 1996) or hold those that are poorly paid (Kinnaird \& Hall, 1994). Nevertheless, women have started climbing the career ladder and nowadays are found in high managerial positions in hotel management.

Moreover, there are some characteristics or traits that hotel managers have. Thus, studies have focused on competencies required by hotel managers, and many different lists of required competencies are developed (i.e., Christou \& Eaton, 2000; Ladkin \& Riley, 1996). Lockyer and Scholarios (2004) identified several personality characteristics in the services industry that are common with those identified in the hospitality industry and included characteristics such as courtesy, consideration, tact, perceptiveness, and good communication skills. In their study, Sehanovic, Zougj, Krizoman, and Bojanic-Glavica (2000), comparing male and female managers, suggested that women showed very good performance on organizational, financial, and management knowledge, manner with people, and knowledge of the economy. They also found that women were very good at organizing work and spotting problems, which they solved quickly. They suggested that both men and women at higher levels delegate authority less than they should.

Iakovidou and Turner (1994) suggested that high standards of maternal comfort and professionalism are required in the hospitality industry in order to develop and maintain good quality customers in a tourism destination. Li and Leung (2001) proposed that due to the lack of time and the varying work schedules, female hospitality managers do not focus on networking, training, and other related activities, which are valued if they wish to progress in their careers. 
Maxwell (1997, p. 233) suggested that female hotel managers communicate better than male hotel managers, especially "in terms of having a deeper insight into and being more interested in their staff”. She also suggested that women possess the management skills that are required by hospitality organizations. These skills include communication, flexibility, the ability to adapt, and teamwork. In reference to managers, Brownell (1994a) suggested that hotel managers delegate, motivate staff, and present information orally and in writing. She continued that they have become good at listening, as part of their communication processes, as well as an information gathering technique, in their effort to assess employees' concerns and the organization's climate. Furthermore, Gherardi (1994) suggested that female attractiveness is exploited within the hospitality industry. She proposed that in work teams, where female and male members are equally represented, the teams work better, showing greater productivity and quality of work.

The leadership qualities of hotel managers may help face the challenges in the industry and the constant changes which include "increasing globalization of the economy, the need to reduce costs, and the pressure to be competitive in a market where there are more global competitors" (Taborda, 2000, p. 41). In addition, Clark, Hartline, and Jones (2009) supported the view of Babakus, Yavas, Karatepe, and Avci (2003) that leadership is important in service organizations, such as hotels, because it may create a transformational climate to enhance employee loyalty and maintain high quality of services provided. They also claimed that little research has been conducted on "the identification of the most appropriate leadership style" in the industry (Clark et al., 2009, p. 210). Furthermore, Galanaki, Papalexandris, and Halikias (2009) and Vakola and Apospori (2007), in their studies in Greece, revealed that there are gender differences in leadership styles between the two genders and that women seem to be restricted in management roles due to family responsibilities and their other roles. Additionally, research on leadership in hospitality has shown that transformational leadership can improve employee commitment, social behavior, and satisfaction (i.e., Marinakou, 2012; Tracey \& Hinkin, 1994). Others, such as Gill and Mathur (2007), supported that empowering leadership improves hospitality employees' behaviors. In general, service managers should provide visible leadership to staff in order to help them accept the nature and the demand of the services provided in the industry (Clark et al., 2009).

In view to the above, it is vital to focus on the employment of women in hotel management and analyze their role and status in the sector in order to highlight the female management and leadership style in hotel management, as well as any opportunities and challenges which women face and which should be addressed by stakeholders.

\section{Methodology}

Management and leadership are social phenomena that rely on the subjective interpretations of both the leaders and their followers (Grint, 2000). Thus, the complexity of the phenomenon demands methodology that can provide access to data that reflect the views of both male and female managers in the industry. The qualitative approach helps to explore the way managers understand and make sense of their lives and how they manage day-to-day situations (Miles \& Huberman, 1994). Hence, the researcher aspired to explore the nature of hospitality management and leadership through the eyes of the participants, by penetrating to the frames of meaning with which these people operate in the organizational context.

Therefore, empirical data are gathered with semi-structured interviews with 15 male and 15 female managers in 5-star hotels in Greece, which are chosen with convenience sampling techniques. The regions chosen for the study are those that have the highest concentration of tourism demand and are considered as 
primary destinations in Greece (Papadimitriou \& Trakas, 2008), i.e., Rhodes, Attica, Crete, Myconos, and Thessaloniki. The hotels belong to the 5-star category and to all types such as resort, city hotel, national or international hotel chain, in order to have a variety of participants and views based on different organizational structures and cultures, as it was difficult to find 15 female general managers in hotels in the areas of study. The semi-structured interviews had a conversational style so that the researcher could understand how each of the participants gave meaning to their work experiences.

The participants in the study are all Greeks. The majority of the managers in the study are single and do not have any children, which shows that despite their age and the fact that they are either married or divorced, the participants spend a lot of time on their careers and at work. The female managers are more likely to remain single and not have children in order to pursue a career. They mainly have undergraduate degrees, and only three participants hold a postgraduate diploma. All, however, have studies in hospitality and/or tourism management. The majority speak at least two foreign languages, as it has been identified as a requirement in hotel management (Christou \& Eaton, 2000).

Thematic analysis has been performed to the interviews in order to answer the research questions. The interviews have been partially transcribed, and although Stelter (2002) claimed that there might be some challenges in using simple word frequency counts to make inferences, themes are developed not only from those that were more frequently discussed, but also based upon the relevant theory discussed in the literature review. Among others, the theme that emerged from the analysis and was discussed in this paper refers to the success factors mainly of female managers in hospitality management in Greece.

\section{Analysis and Results}

The participants expressed their views on three main topics as they emerged from the data analysis. Firstly, the glass ceiling issues in hotel management, then the leadership style that the managers adopt, and finally the factors that lead to successful management in the hospitality industry in Greece. The female managers in the study stressed the barriers they face and the factors that contribute to the glass ceiling phenomenon, whereas the male managers were concerned with the phenomenon, but only in reference to their female counterparts. Nevertheless, some issues on the glass ceiling are presented in this paper in an effort to show how female managers deal with them, as the focus of this paper is mainly on the leadership and the management style that is adopted.

In reference to the glass ceiling, male managers believe that it is more difficult for women to work in the industry, as it requires working long hours, sometimes sacrificing family and personal lives and more often moving around to different tourism destinations in order to advance. More specifically, one female manager (assistant general manager) admitted that she did not accept an offer to become a general manager, because as she said:

My own desire to spend more time with my children will probably ensure that I stay where I am for convenience. I guess many capable women will not make it into the positions of influence for these reasons. Unfortunately, the women making it are usually childless and are therefore less aware of the work conditions that need to change.

Nevertheless, another female manager (general manager) said, "If you manage your time, then you can balance work with family”. These views are also supported by similar studies such as Ng and Pine (2003) and Knutson and Schmidgall (1999) who considered hard work and commitment at work as major contributors to 
managers' success. These confirm Baum's (2013) view on the characteristics of hospitality management. He stressed hands-on work, operational control, and hard work in combination with frequent interaction with staff and other members of the organization as part of their tasks. Female managers in the study claim that they work many hours and sometimes more hours than the male managers, because they have to prove their skills. Although, the female managers that have a family find it difficult to balance work with family obligations, they accept the challenge and develop such skills and competencies that allow them to perform well. For example, one front office manager said:

If you want to excel and advance, if you want your customers and the management to be happy, you have to be there whenever it is required. I may come in the middle of the night because we have 300 guests checking in. I will help with everything, even the bellboy to carry the suitcases...

Thus, hotel managers have to develop competencies across a variety of departments, offering more career opportunities and higher salary levels (Carbery, Garavan, O’Brien, \& McDonnell, 2003). Interestingly, however, very few female managers expressed the desire to become general managers in their hotels, they desire to have a successful career, whereas the male managers have planned their careers and they showed their egos.

Sex and gender discrimination is still evident in the hotel sector, nevertheless, the situation is getting better, and women managers are given more opportunities to pursue a managerial career. This point was made by both male and female managers, and more specifically, a food and beverage female manager admitted that although it is difficult to penetrate the kitchen's male-dominated environment, it is possible with the proper attitude, behavior, and knowledge confirming the study of Knutson and Schmidgall (1999). Additionally, both male and female managers propose that knowledge of the industry, the job, and the prior studies as well as experience help them gain the respect of their peers and superiors. Further, female participants value more than the male managers delegation and sharing the decision-making with their staff. They propose that this allows them to have more time to spend on staff training and planning and organizing their jobs. For example, a female manager said:

Within the industry, I have never felt my being a woman hindered my growth or the respect that I have received for my experience and knowledge. It is individuals outside the industry who will, for example, seek the acceptance of the male during a meeting instead of the woman, even though the woman is the decision-maker. That always makes for an interesting scenario!

Female managers in contrast to the male managers in the study claim that patience, smile, and humor may help deal with challenging situations and circumstances with all the stakeholders. Brownell (1994a) proposed that the interpersonal skills and determination are success factors in hotel management, and women in the current study are found to acquire these. In addition, female managers in the study propose that they should be as assertive as men, enthusiastic, and caring for their staff. Purcell (1996), in her study, also suggested that "the right kind of personality” is an important element (p. 18). Another success factor is to acknowledge the mistakes and apologize when necessary.

Further, female managers claim that they are trying to change today's management culture and style. Thus, they provide a more nurturing and accommodating environment. Therefore, they listen to their staff, they respect their opinions, and they discuss any problems at work. In this way, they encourage a team-based management style that generates more mentoring opportunities for employees through the environment and the working climate. Finally, they all claim that the culture is changing and women are given more opportunities to progress. This point affirms Powell and Graves (2003) who suggested that companies play a role in women's 
success by adopting strategies to advance their careers or by erecting barriers that might prevent women from advancing. Although, Baum (2013) found that women in the industry are responding realistically to a situation in which they view an impossible future, female managers in this study are more optimistic about the current situation and the position that women hold in the Greek hospitality industry. They believe that they are not far away from placing women in top positions, as one noted that:

It is true that women work very hard and they are more in the hospitality industry. You do not find many women at managerial positions, but the numbers of women are growing very fast. You find many female managers in big hotel chains mainly. I strongly believe that women are more effective, they have very good communication skills that are required in the industry, they make very careful steps, and they create very good reputation.

Evidently, male and female managers agree on some competencies and skills that are required to advance and progress in hotel management, but the two genders perceive differently the barriers and obstacles to their careers. For example, female managers value the relationships with their colleagues or supervisors, whereas male managers value their status in their positions, which affirms Iverson's (2000) study.

On the contrary, male managers believe that both male and female managers are equal and equally treated; they have the same way of thinking and professional values. When they get married, they both value their families and think that family comes first, and thus, for both, it is difficult to progress considering the patriarchic culture in Greece and the difficulties they may face with regard to their responsibilities towards family and work. Furthermore, male participants add that their female colleagues are as good as they are, and they have a bright future as long as they continue the hard work, despite the sex and gender stereotypes that persist in the Greek culture. Interestingly, one male food and beverage manager stated "make a woman's kind of work and it will be work that will blossom”.

\section{Implications for Hotel Management}

The results of the current study provide directions for managers in hotels, as they suggest that women may be successful managers, although they face many challenges in their careers. As Powell and Graves (2003, p. 153) suggested, organizations should be ready to address any discrimination that occurs in the companies, especially "when they embrace stereotypical views or display prejudices towards members of one sex as leaders". Thus, they should use the legal framework that supports equality at work. They should provide female managers with the adequate policies to support them in terms of balancing family with work. Such policies include the leave of absence when people are getting married, when they have children, time off during their pregnancies, or time for their children, i.e., to get them to the doctor. Sometimes, however, the female managers in the study said that the employees, the other managers, and the top managers' behaviors may undermine these privileges. Thus, they do not take advantage of this policy, "only when it is necessary". Therefore, organizations should act to reduce these beliefs and attitudes towards female managers (Powell \& Graves, 2003) and provide them with the environment to use their skills and talents that are found to be effective in hotel management. The culture in Greek organizations, including hospitality organizations, has an impact on female and male managers. The demanding and challenging environment forces women to think carefully before starting a family and to manage their personal lives so well that it will not influence their performance and productivity. Such stereotyping can be detrimental to their advancement, not only because they have to carefully plan their lives, but also because their employees perceive them differently, or it influences whether they will be promoted, further trained, or be given the opportunities to grow within the company. 
This study suggests that as the hospitality industry faces uncertainty and fierce competition that threaten its effectiveness, female managers may be employed as they are flexible and may help the organization to adapt to new demands. The findings suggest that attitudes towards women as managers have changed and they may now undertake leadership roles, as their female traits are significantly valued in hotel management. Female managers have the skills and competencies required to succeed in this demanding industry. Further research may be conducted in other countries to explore the positions of women in hotel management and provide more general views on the topics and suggestions on how women may overcome the problems and the challenges as well as how hotels may create more opportunities for women managers.

\section{References}

Babakus, E., Yavas, U., Karatepe, O. M., \& Avci, T. (2003). The effect of management communication to service quality on employees' affective and performance outcomes. Journal of the Academy of Marketing Science, 31(3), 272-286.

Baum, T. (2013). International perspectives on women and work in hotels, catering, and tourism. Geneva: International Labor Organization.

Biswas, R., \& Cassell, C. (1996). Strategic HRM and the gendered division of labour in the hotel industry: A case study. Personnel Review, 25(2), 19-34.

Brownell, J. (1994a). Women in hospitality management: General managers' perceptions of factors related to career development. International Journal of Hospitality Management, 13(2), 101-117.

Brownell, J. (1994b). Personality and career development: A study of gender differences. Cornell Hotel and Restaurant Administration Quarterly, 35(2), 36-43.

Carbery, R., Garavan, T. N., O’Brien, F., \& McDonnell, J. (2003). Predicting hotel managers' turnover cognitions. Journal of Managerial Psychology, 18(7), 649-679.

Christou, E., \& Eaton, J. (2000). Management competencies for graduate trainees. Annals of Tourism Research, 27(4), $1058-1061$.

Clark, R. A., Hartline, M. D., \& Jones, K. C. (2009). The effects of leadership in hotel employees' commitment to service quality. Cornell Hospitality Quarterly, 50(2), 209-231.

Erkutlu, H. (2008). The impact of transformational leadership on organizational and leadership effectiveness: The Turkish case. Journal of Management Development, 27(7), 708-726.

Eurostat. (2009). Tourism statistics. Retrieved from http://epp.eurostat.ec.europa.eu/statistics_explained/index.php/ Tourism_statistics

Galanaki, E., Papalexandris, N., \& Halikias, J. (2009). Revisiting leadership styles and attitudes towards women as managers in Greece. Gender in Management: An International Journal, 24(7), 484-504.

Gherardi, S. (1994). The gender we think, the gender we do in our everyday organizational lives. Human Relations, 47(6), 591-610.

Gill, A. S., \& Mathur, N. (2007). Improving employee dedication and pro-social behavior. International Journal of Contemporary Hospitality Management, 19(4), 328-334.

Grint, K. (2000). The arts of leadership. Oxford: Oxford University Press.

Iakovidou, O., \& Turner, C. (1994). The female gender in Greek agrotourism. Annals of Tourism Research, 22, 481-484.

International Labour Office [ILO]. (2009). Facts on the hotel and catering industry. Retrieved from http://www.ilo.org/communication

Iverson, K. (2000). The paradox of the contented female manager: An empirical investigation of gender differences in pay expectation in the hospitality industry. International Journal of Hospitality Management, 19(1), 33-35.

Jordan, F. (1997). An occupational hazard? Sex segregation in tourism employment. Tourism Management, 18(8), 525-534.

Kinnaird, V., \& Hall, D. (1994). Tourism: A gender analysis. Chichester: John Wiley \& Sons.

Knutson, B. A., \& Schmidgall, R. S. (1999). Dimensions of the glass ceiling in the hospitality industry. Cornell Hotel and Restaurant Administration Quarterly, 40(6), 64-75.

Ladkin, A., \& Riley, M. (1996). Mobility and structure in the career paths of UK hotel general managers: A labour market hybrid of the bureaucratic model? Tourism Management, 17(6), 443-452.

Li, L., \& Leung, R. W. (2001). Female managers in Asian hotels: Profile and career challenges. International Journal of Contemporary Hospitality Management, 13(4), 189-196. 
Lockyer, C., \& Scholarios, D. (2004). Selecting hotel staff: Why best practice doesn’t always work? International Journal of Contemporary Hospitality Management, 16(2), 125-135.

Marinakou, E. (2012). Gender and leadership in hospitality: Women in hospitality management and leadership in Greece. LAP LAMBERT Academic Publishing.

Marshall, J. (1984). Women managers: Travellers in a male world. Chichester: John Wiley \& Sons.

Mavridis, D. (2002). Cherchez la Femme-Women as managers in Greek corporates: An empirical investigation. Equal Opportunities International, 21(7), 21-36.

Maxwell, G. A. (1997). Hotel general management: Views from above the glass ceiling. International Journal of Contemporary Hospitality Management, 9(5/6), 230-235.

Mihail, D. (2006). Gender-based stereotypes in the workplace: The case of Greece. Equal Opportunities International, 25(5), 373-388.

Miles, M. B., \& Huberman, A. M. (1994). Qualitative data: An expanded sourcebook. Thousand Oaks: Sage Publications.

Ng, C. W., \& Pine, R. (2003). Women and men in hotel management in Hong Kong: Perceptions of gender and career development issues. International Journal of Hospitality Management, 22(1), 85-102.

Nickson, D., \& Warhust, C. (2001). From globalization to internationalization to Americanization: The example of "little Americas” in the hotel sector. In M. Hughes, \& J. Taggart (Eds.), Multinationals in a new era-International strategy and management (pp. 207-225). Basingstoke: Palgrave.

Ntermanakis, N. P. (2003). Gender pay gap in selected industries and occupations in Greece. Athens: Greek Research Centre for Gender Equality, Athens (in Greek).

Papadimitriou, P., \& Trakas, T. (2008). The changing face of the Greek hospitality market. Retrieved from http://www.4hoteliers.com/4hots_fshw.php?mwi=3649

Papalexandris, N. (2008). Greece: From ancient myths to modern realities. In J. Chhokar, F. Broadbeck, \& R. House (Eds.), Culture and leadership across the world: The GLOBE book of in-depth studies of 25 societies (pp. 767-802). London: Lawrence Erlbaum Associates.

Pettraki-Kottis, A., \& Ventoura-Neokosmidi, Z. (2004). Women in management in Greece. In M. Davidson, \& R. J. Burke (Eds.), Women in management worldwide: Facts, figures, and analysis. Burlington: Ashgate.

Powell, G. N., \& Graves, L. M. (2003). Women and men in organizations. Thousand Oaks, California: Sage Publications.

Purcell, K. (1996). The relationship between career and job opportunities: Women's employment in the hospitality industry as a microcosm of women's employment. Women in Management Review, 11(5), 17-24.

Scott, J. (1995). Sexual and national boundaries in tourism. Annals of Tourism Research, 22(2), 385-403.

Sehanovic, J., Zougj, M., Krizoman, D., \& Bojanic-Glavica, B. (2000). Some characteristics of women managers in the hotel industry. International Journal of Contemporary Hospitality Management, 12(4), 267-270.

Stelter, N. Z. (2002). Gender differences in leadership: Current social issues and future organisational implications. Journal of Leadership and Organisational Studies, 8(4), 88-100.

Taborda, C. G. (2000). Leadership, teamwork, and empowerment future management trends. Cost Engineering, 42(10), 41-44.

Thomas, A. B. (2005). Controversies in management, issues, debates, answers (2nd ed.). New York, N.Y.: Routledge/Taylor \& Francis Group.

Tracey, J. B., \& Hinkin, T. R. (1994). Transformational leaders in the hospitality industry. Cornell Hotel and Restaurant Administration Quarterly, 35(2), 18-24.

Vakola, M., \& Apospori, E. (2007). Women and management. Athens: Sideris (in Greek).

Woods, R. H., \& Viehland, D. (2000). Women in hotel management. Cornell Hotel and Restaurant Administration Quarterly, 41(5), 51-54. 